\title{
Digital Governance Model for Big Data Era----Based on Typical Practices in Singapore
}

\author{
Ting Lei", Yuwei Tang \\ School of Public Administration, University of Electronic Science and Technology of China, Chengdu, China \\ Email address: \\ 906398884@qq.com (Ting Lei), 454722360@qq.com (Yuwei Tang) \\ ${ }^{*}$ Corresponding author
}

To cite this article:

Ting Lei, Yuwei Tang. Digital Governance Model for Big Data Era----Based on Typical Practices in Singapore. Humanities and Social Sciences. Vol. 7, No. 2, 2019, pp. 76-82. doi: 10.11648/j.hss.20190702.15

Received: April 9, 2019; Accepted: May 23, 2019; Published: June 15, 2019

\begin{abstract}
Research background] Different social forms determine different social governance models. With the development of the Internet of things, cloud computing and artificial intelligence, digital governance has entered the big data era. [Research questions and methods] What should be the digital governance model for the big data era? Krassimira believe that applying digital governance theory to guide smart city practice is an important step in governance theory in the field of urban governance. Singapore's "Smart nation 2025" is the first blueprint for a smart nation in the world. Taking the practice of Singapore's "smart nation 2025 " as a case study, based on the theory of digital governance, from the three dimensions of digital economy, digital government and digital society, using the "institutional-organization-technology-behavior" analysis framework, this paper analyzes the context framework of Singapore's digital governance model, and summarizes the typical characteristics of Singapore's digital governance model. [Conclusion] The study found that Singapore has established a digital governance model in which governments, economic society, and civil society can collaborate and interact. Singapore has accumulated a wealth of digital governance experience[Contribution and limitation] Singapore's urban development is highly mature, and its digital governance has typical particularity, but the experience and enlightenment of Singapore's digital governance practice can provide a reference path for improving China's digital governance ability.
\end{abstract}

Keywords: Digital Governance Theory, Digital Governance Model, Experience and Enlightenment, Smart Nation 2025

\section{Introduction}

With the development of the Internet of things, cloud computing and artificial intelligence, urban governance has entered the era of big data, and at the same time, it has also given birth to the combination of Internet digital technology and governance theory in the data era. Give birth to a new public management paradigm-digital governance theory. The theory of digital governance advocates the use of digital technology and information system in the public sector, promotes the flattening reform of public sector management mechanism, reshapes the government process, and then realizes the process of good governance in which public power is shared with the people. [1] Patrick Dunleavy, a British scholar, is the representative of digital governance theory. He systematically expounds the main contents and advantages of digital governance theory.
Smart cities use digital technology or information and communication technology (ICT) to improve the quality and performance of urban services, and change the mode of interaction among governments, enterprises and citizens through big data, cloud computing and the Internet of things. [2] Building a smart city requires a lot of basic city information, which is premised on big data applications. The digital governance of smart cities requires the integration of information resources in all aspects of politics, economy and culture. Big data-assisted smart city construction is an important practice of digital governance. [3]

Based on the Global Connectivity Index (GCI) of national digital transformation assessments in 2018, Singapore ranks second in the world, demonstrating Singapore's strong global digital connectivity. As a famous developed city, Singapore is 
one of the earliest countries in the world to establish the construction strategy of an smart nation. Singapore has been working on a long-term strategic layout since the 1980s, launching the "Smart nation 2015" and "Smart nation 2025" programs in 2006 and 2016, respectively, aimed at building the world's first smart nation [4]. The core idea of Singapore's smart nation construction is "people-oriented", and relying on the development of the Internet of things, big data and AI technology, joint industry associations to promote the digital transformation of enterprises and support the development of the information industry; Integration of real-time urban monitoring of the Internet big data, to create a fine service of the overall government; improve the digital literacy of citizens, promote community construction. Up to now, it has been formed with the government as the driving body and in-depth cooperation with enterprises and citizens, involving many dimensions, such asdigital economy, digitalgovernment, digital society and so on. It includes the construction framework of smart nation in many aspects, such as technological basis, individual behavior, organizational model, institutional framework and so on.

As an important part of the world economy, China is also actively promoting the digital transformation of state governance. On December 8, 2017, at the Second National Big Data Strategy Collective Learning Conference of the Political Bureau of the Communist Party of China, President Xi Jinping emphasized that China should actively promote the implementation of the national big data strategy, accelerate the construction of digital infrastructure, and accelerate the construction. Digital China will better serve China's economic and social development and improvement of people's lives.[5]Although China has already practiced digital governance in cities such as Zhuhai and Nan tong, China is at a critical stage of social transformation, and urgently needs mature experience in digital governance practices to sort out by summarizing Singapore's digital governance model. It can provide reference path and valuable experience for the development of digital governance in China in the future.

\section{Literature Review}

The theory of digital governance originated in the 1990s, and with its unique technology orientation, it became the new governance idea of the public sector during the development of information technology. With the rapid development of information technology, digital governance has become an important issue in the field of governance. Using "digital governance" as a search keyword, 2,100,000 results have been retrieved in Google Scholar, including a large number of documents and books. These books provide a detailed introduction to the background, main points, development history and typical practices of digital governance theory.

The development of digital governance theory has gone through four stages. The first stage is the early stage of digital governance theory (before 2005). Scholars mainly focuses on the research of the two issues of network social democracy, organizational system and information technology change. In terms of social democracy issues, Saskia Sassen emphasizes the importance of smooth communication channels. In order to ensure the smooth flow of online democracy under the guidance of digital governance theory, he believes that it is especially necessary to strengthen cooperation and digital legislative activities among multiple subjects. [6-7] In the relationship between organizational system and information technology change, Jeffrey Roy discussed the two aspects of the relationship between organizational system and information technology change when discussing e-governance and digital government in Canada. The first is cross-sectoral governance, and the second is the role of organizational culture and people. [8] The second phase emphasizes demand-based holistic research and digital transformation research (2006-2010). Patrick Dunleavy advocates the continuous introduction of emerging data processing technologies such as big data and cloud computing to strengthen the development of collaborative public services in the digital age. And continue to enrich the "toolbox" of the public sector public management system. [9] Xu Xiaolin and Zhou Lixin tried to use the digital governance theory to construct a system for good governance of the city government. They believe that digital governance refers to the interaction of information technology in government and civil society, economic society and internal government operations, reshaping the relationship between government and administrative processes, simplifying the handling of public affairs, and improving the degree of democratization of governance models. [10-11] The research focus of the third stage of digital governance theory is the comparison of citizen participation and multi-angle. Krassimira Antonova Paskaleva and Roberto Garcia Alonso also cut through the perspective of smart city and expounded the guiding significance of digital governance theory to practice. Applying digital governance theory to guide smart city practice is an important step in the field of governance theory to urban governance. Digital governance theory helps city managers make better decisions from theoretical guidance, democratic activities, decision-making processes and citizen participation. Further enhance the competitiveness of the city. [12] Digital governance theory guides smart city practices to help promote community integration and innovative forms of citizen participation. [13] Based on the research and experience of Zhuhai Hengqin Smart City Construction, Zeng Dong and Guo Peiwen have drawn a series of inspirations from digital governance practices to the good governance of Chinese cities. [14]

\section{Case Overview}

\subsection{The Development of the Singapore's Smart Nation}

The construction of the smart nation in Singapore has gone through three stages, each of which has a distinct goal orientation. 
The first stage is the preparatory phase for the construction of the smart nation (1980-2005). In 1980, the Singaporean government put forward the "National computerization Plan", which aims to promote the use of computers between the government and enterprises in Singapore. In 1991, the Government of Singapore put forward the "National Science and Technology Plan", which aims to solve the problems of urban information connectivity and data sharing at the administrative and technical levels, and to eliminate the "information isolated island". The Singaporean government has also put forward the "Information and Application Integration platform" plan, which hopes to promote the rapid growth of information, communications, and technology in Singapore's economy and modern service industries. As a result, the information and application integration platform has become an important economic platform in Singapore, and every industry has the ability to adopt the ability to operate digitally. [15] Through these three basic preparation plans, Singapore's basic digital facilities have developed rapidly, providing a basis for the subsequent construction of the smart nation.

The second phase is the initial implementation phase of the smart nation (2006-2015). The Government of Singapore has launched the "Smart nation 2015" project, the core of which is to enhance the capacity of cross-regional and cross-industry resource integration. To achieve its goals, Singapore has implemented four major strategies, including building a new generation of information and communication infrastructure, developing a globally competitive information and communications industry, developing information and communication human resources that are well-versed in information communication and internationally competitive, and achieve transformation of key economic sectors, governments and society. [16] At this stage, the transformation policy represented by the "iGov" and the policy system on intelligent infrastructure construction have been introduced.

The third phase is the accelerated implementation phase of smart nation construction (2016-2025). The Singaporean government has launched a 10-year plan called "Smart nation 2025". With the development of artificial intelligence, the Internet of things and big data technology, Singapore is facing increasing global competition. At this stage, the Singapore government put forward a plan to build the first smart nation, and issued documents such as "Digital Economy Framework", "Digital Preparation Blueprint" and "Digital Government Blueprint" in 2017, which have become the three supporting strategies for the construction of an smart nation. The policy characteristics of this stage are as follows: starting with the three major construction subjects of enterprises, government and citizens, more comprehensive and systematic, emphasizing citizen demand as the center, keeping up with the forefront of the development of artificial intelligence and Internet of things technology, And developed a more in-depth and standardized industry standards.

\subsection{Overview of Singapore's "Smart Nation 2025"}

In the construction of the smart nation, the Singapore government closely follows the social construction subjects such as the government, enterprises and citizens, and involves political, economic and cultural urban governance areas, and has formed a clear and comprehensive policy system. At present, the most important guiding plan for the construction of the smart nation in Singapore is "Smart nation 2025", which is the world's first blueprint for smart nation. It is a master plan for the construction of smart nation in Singapore, it build a full coverage of urban data collection, connectivity and analysis platform, through the analysis of the city big data to predict the needs of citizens, to provide refined public services, Singapore will become the first smart nation.

In order to support Singapore's "smart nation 2025" construction vision, the Singapore government has successively promulgated three major policies in 2017: the "Digital Economy Framework", the "Digital Government Blueprint", and the "Digital Readiness Blueprint". It has issued the development strategy and concrete plan of digital economy, digital government and digital society in order to realize the construction of smart nation. In terms of economic construction, the main body is the government support policy to promote the digital transformation of Singapore's enterprises and the training policy to provide employment opportunities for the people, Involved in various aspects such as smart industry standards and smart industry laws, it is expected that Singapore will become the leader of the digital economy. In terms of government construction, the construction of the Whole of Government(WOG) universal digital platform and the digitalization of public officials is the core of the policy, and the government's public services are expected to be more streamlined and powerful. In terms of social construction, it focuses on the improvement of national digital literacy and the construction of communities through technological transformation, ensuring that every Singaporean can become the center of Singapore's smart nation, and every Singaporean can experience the benefits of technology. It has also introduced people's livelihood policies such as intelligent transportation construction, smart home and smart medical care, and is eager to improve citizens' life satisfaction through the development of modern technology.

\section{Case Study}

\subsection{Research Method}

This study uses a single case study method based on the Singapore government's archives, news and policy texts, and takes Singapore's smart nation practice as the research object. Based on the theory of digital governance, this study uses the "institutional-organization-technology-behavior" framework to analyze Singapore's digital governance model from the three dimensions of digital government, digital economy and digital society, and summarizes the main experiences of digital governance in Singapore. Figure 1 is the analytical framework of this paper. 


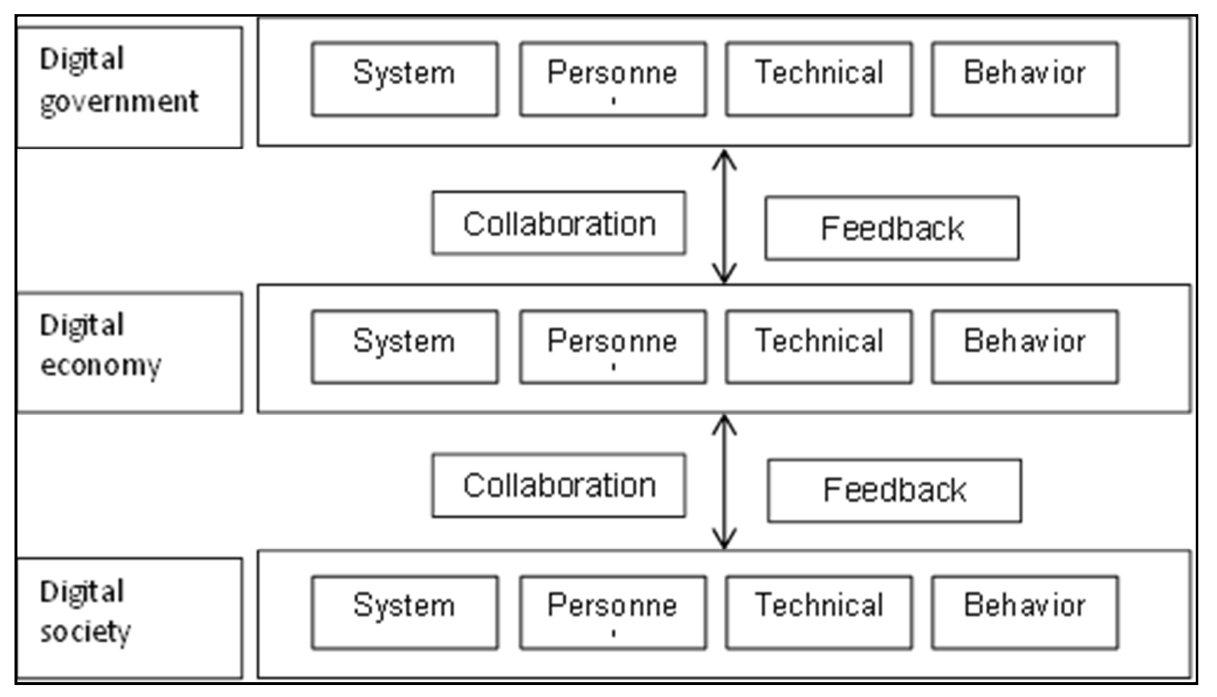

Figure 1. Case analysis framework.

\subsection{An Analysis of the Practice of Singapore's Smart Nation}

\subsubsection{Implementation Path of Digital Government}

In terms of system, the "Digital Government Blueprint" has become the general framework for digital government construction. Based on the previous e-government master plan, through the better use of data and new technologies, the Whole of Government (WOG) universal digital and data platform is constructed. Make public services more refined, thereby promoting the broader digitalization of the economy and society, and supporting the construction of smart nations. In terms of personnel, the Chief Digital Strategy Officer was appointed to lead and implement the digital programs within their ministries and their respective agencies. Information technology officials will support them from a technical perspective. At the middle management and work level, the Singapore government will also help officials understand the support that technology can provide in government decision-making and operations. Explain to the technical staff the relevant processes of government operations, help them understand the government's business needs, and design effective technical solutions. Technically, Singapore's National Technical Services Department provides basic technical support for the digitalization of the Singapore government. Key tools include building data centers and hosting platforms, building an infrastructure to support applications, building microservices libraries, building national digital identity systems, and designing digital solutions that best meet the needs of the public. In terms of behavior, the Singapore government integrates public services around the needs of citizens and businesses, and strengthens policy and technology integration, and establishes a digital platform for multi-government departments to work together to enhance the digital capabilities of government departments to pursue innovation.

\subsubsection{Implementation Path of Digital Economy}

In terms of system, in order to realize the transformation of
Singapore's digital economy, the Singapore government has successively promulgated the Electronic Transactions Act, the Intellectual Property Act and the Cyber Security Act, which explicitly proposed to protect the copyright of the Internet, promote the development of information, and establish a new A goal of digital infrastructure and better citizenship for citizens. The Digital Economy Framework proposes the future vision of Singapore's digital economy construction from a strategic perspective, and has formulated the industrial plan for Singapore's digital economy, clarifying the digital transformation of enterprises, changing the way companies operate, creating new growth prospects for enterprises, and providing new benefits for the people. Employment opportunities will build Singapore into the development goal of the world's leading digital economy. In terms of personnel, the Singapore government has specially established the "Singapore Information and Communication Media Development Authority", which will lead the formulation of informatization construction and development policies in various fields of Singapore at the national level and across the country. The "Singapore Information and Communication Media Development Authority" has unified leadership of 21 professional committees, ICT committees, public sector ICT steering committees, and public domain ICT review committees to perform functions such as decision-making, coordination, management, and execution. Technically, the Deepening Ecosystem Capacity Program, launched in 2017, defines the in-depth capacity building of cutting-edge technologies such as artificial intelligence, big data, the Internet of things, and virtual reality. For the artificial intelligence industry, the government will provide policy frameworks and industry guidelines to help the development of artificial intelligence industry capabilities; for the Internet of things industry, the government will establish partnerships with the industry, release industry standards to strengthen industry capabilities, and realize the development of Internet of things solutions. For the virtual reality industry, the government will assist Singaporean 
media companies and professionals to enhance the widespread use of virtual reality technology through technology development. In terms of behavior, the Digital Economy Framework contains three action strategies: First, it emphasizes accelerating the digitization of Singaporean companies, increasing productivity, increasing efficiency and profitability, and increasing new employment opportunities. The second is to emphasize competition, guide enterprises to integrate customer needs, and cultivate a new competitive integrated ecosystem through digitalization to enhance the economic benefits of the industry. The third is to emphasize change and develop the digital industry as the engine and driving force of economic growth for the next generation industry, and promote the digitization of all industries.

\subsubsection{Implementation Path of Digital Society}

Institutionally, the Singapore government has introduced the "Silver Information and Communication Program", "Digital Work Future Skills Program" and "IT Disability Plan" to encourage older people to master IT skills and information communication capabilities to provide Singapore citizens with a future life. Digital competency training to provide accessible IT technology services to vulnerable groups. The Digital Preparation Framework, promulgated in 2017, is a complete framework for the digital society and will provide a wide range of technical assistance to promote citizen digital literacy and encourage everyone to strengthen digital preparation to ensure that people become the centre of Singapore's smart nation. People can improve their quality of life through technology. In terms of personnel, the Digital Preparedness Planning Office was established by the Ministry of Communications and Information in May 2017 to be responsible for promoting the national strategy for digital preparation, and in August 2017 was convened by the Ministry of Communications and Information (MCI) from the public sector, the private sector and the representatives of the public and the Digital Society Working Group promoted the synergy between the public sector, the private sector and the public in the field of smart nation construction and resources, and worked with the three parties to develop relevant digital social policies and design plans. Monitoring progress and effectiveness initiatives, conducting management marketing and evaluation. Technically, in collaboration with the private sector, the Tech Able platform was established, which includes support for innovation centers and engineering support technology centers. Tech Able platform is Enabling Village's integrated assistive technology space, providing technology demonstration and complementary assessment services to citizens while providing a support platform for digital community building. The Singapore Technology Bureau partnered with private technology companies to launch the Sing Pass platform, an app that allows citizens to make more transactions on the go. In terms of behavior, the "Digital Readiness Blueprint" provides a comprehensive guide to digital social action. First, it requires technical design and transformation to expand and enhance the inclusiveness of digital access. Second, it plans to pass digital training through a series of digital capabilities. Literacy is integrated into national consciousness;. Finally, it is emphasized that communities and enterprises can widely use information technology to solve specific problems.

\section{Experience and Inspiration}

\subsection{The Core of Digital Governance in Singapore Is People-Oriented}

The core of digital governance in Singapore is people-oriented and serving the people. Pay attention to citizens' better life in digitalization, improve citizens' quality and better participate in digital governance. Emphasize the human rights and sovereignty of citizens' participation in governance, and also pay attention to the dominant position of government participation in governance.

China's smart city practice in Longyan City, Shenzhen City and Zhuhai City reflects the concept of "people-oriented" to a certain extent. The local government hopes that the public will experience more high-quality and convenient services through innovation of governance methods. However, due to the interference and constraints of various factors, the development and application of smart city practices such as various software still have limitations such as limited service content and narrow coverage of service population.

Integrate services around the needs of citizens and businesses to further enrich the platform service content and expand the coverage of the digital platform target population. In the face of target groups such as the elderly, the disabled and foreigners, special services should be customized and developed, and training and guidance should be given to their use methods. Formulate a long-term training plan for digital literacy for all, so that smart citizens, smart officials and smart cities complement each other to promote better development of the country and the city and improve people's living standards.

\subsection{Singapore Digital Governance Emphasizes the Government Leadership}

Singapore has established digital offices, chief digital officers and digital community committees in the area of digital governance to promote the development of the digital economy, digital government and digital communities. These organizations are important pillars of Singapore's promotion of digital reform and Singapore's digital governance framework. It has jointly promoted the development of digital governance in Singapore.

In terms of public organization and institutional setup, China has set up a unified leadership of the Big Data Administration, and various government departments have implemented government planning and government governance activities through the digital governance of government service platforms.. However, among the specialized agencies represented by the Big Data Administration of Longgang District, Shenzhen, the Digital Longyan Construction Office of Longyan City and the Big Data Development Administration of Xilin Gol League of 
Inner Mongolia, most of its functions are the sharing and application of big data and the coordination and interaction of various government departments on the government service platform, but it lacks the overall planning and long-term plan for the development and construction of local smart cities and the practice of digital governance. Therefore, in the process of digital governance public organization and institution construction, the positive role of professional functional departments in digital governance practice activities and smart city development and construction should be brought into full play. Through the investigation of local conditions, the study and reference of domestic and international digital governance practices, build a digital governance model closely combined with the actual situation of the city, formulate a digital governance practice plan that complements the local overall plan, and give full play to the leading role of the department in the practice of digital governance.

\subsection{Singapore Digital Governance Supports Multi-subject Participation}

The Singapore government has set up a digital industrial park to further improve the digital industry system and support the digitalization of enterprises to promote digital governance. The government has also worked with industry associations to develop digital industry standards to jointly develop industry digital development strategies.

Up to now, although many industries, such as finance, medical care, health and enterprises, such as Alibaba, Huawei, and Shenzhou Holdings, have participated in the practice of digital governance, China still lacks the corresponding standards for the intelligent industry and the relevant laws on the intelligent industry, the participation of various industries and enterprises in the practice of digital governance is still not standardized and inadequate. Therefore, governments across China should formulate corresponding digital industry standards and digital industry laws based on local specific practices and national conditions to standardize and coordinate the participation behaviors and activities of various enterprise units in digital governance practices. In addition, for artificial intelligence, Internet of Things, virtual reality and other industries, the government should also provide corresponding policy frameworks and industry guidelines, and develop corresponding industry standards to promote cooperation with related industries and promote the development of emerging industries.

Singapore is also concerned about the innovation of self-organizing and guiding mechanisms for public participation in digital governance. Singapore pays particular attention to public participation in digital governance practices. It not only provides citizen network assistance to help citizens who do not use the Internet to upgrade their digital skills, applies for services through government service websites, but also encourages communities to set up committees to participate in community digital governance.

In the digital governance practice activities in various places, the public mainly participates in citizen participation through application software, telephone hotline, government service platform and government affairs center. However, the technical requirements and physical limitations of these methods still keep some people out of the threshold of digital governance engagement. Therefore, the Chinese government should innovate the way the public participates in digital governance, further reduce the technical requirements and material restrictions of public participation, and open up public participation channels so that every citizen can participate in digital governance practices. In addition to technological innovation and progress, the Chinese government should also attach importance to the important role of grass-roots mass autonomous organizations such as neighborhood committees and third-party forces such as volunteer associations, through multi-party cooperation and joint efforts. Guide the masses to consciously join the practice of digital governance.

\section{Conclusion}

The Singaporean government, which is the driving force behind Singapore's smart nation-building, has set up a special government agency to be responsible for digital promotion. Singapore has established a digital governance model of government, economic society represented by enterprises and civil society represented by the public. This model is a mature experience that China urgently needs to learn from in the face of social transformation. This study is based on second-hand data and information, there are some limitations, but the perfect analysis framework can provide reference for the future research of data governance.

\section{Acknowledgements}

Thank you for the support provided by the Graduate Social Research Fund (YH20181201) of the University of Electronic Science and Technology (UESTC) for this article.

\section{References}

[1] Janowski T, Estevez E, Baguma R. Platform governance for sustainable development: Reshaping citizen-administration relationships in the digital age $[\mathrm{J}]$. Government Information Quarterly, 2018, 35(4): S1-S16.

[2] Wu Y, Zhang W, Shen J, et al. Smart city with Chinese characteristics against the background of big data: Idea, action and risk [J]. Journal of Cleaner Production, 2018, 173: 60-66.0.

[3] Source of data: https://www.smartnation.sg/why-Smart-Nation

[4] Keane M. Internet+ China: Unleashing the innovative nation strategy $[\mathrm{J}]$. International journal of cultural and creative industries, 2016, 3(2): 68-74.

[5] Curtis S. Cities and global governance: State failure or a new global order? [J]. Millennium, 2016, 44(3): 455-477.

[6] Zhi, Y. F. 2002. E-government in digital era: Concept, practice, and development. J. International Journal of the Computer. (October. 2002), 1-22. 
[7] Roy, J. 2001. E-governance \& Digital Government in Canada. J. Ifip Conference on Towards the E-society: E-commerce, 845-856.

[8] Choi I. Digital era governance: IT corporations, the state, and e-Government [J]. 2016.

[9] McCann E. Governing urbanism: Urban governance studies 1.0, 2.0 and beyond [J]. Urban Studies, 2017, 54(2): 312-326.

[10] Meijer A J, Gil-Garcia J R, Bolívar M P R. Smart city research: Contextual conditions, governance models, and public value assessment [J]. Social Science Computer Review, 2016, 34(6): 647-656.

[11] Lim C, Kim K J, Maglio P P. Smart cities with big data: Reference models, challenges, and considerations [J]. Cities, 2018, 82: 86-99.
[12] Ruhlandt R W S. The governance of smart cities: A systematic literature review [J]. Cities, 2018, 81: 1-23.

[13] Liou K T. Government reform, public governance, and Chinese economic development [J]. Journal of Chinese Governance, 2017, 2(3): 255-270.

[14] Khatoun R, Zeadally S. Smart cities: concepts, architectures, research opportunities [J]. Commun. Acm, 2016, 59(8): 46-57.

[15] Yigitcanlar T, Kamruzzaman M. Does smart city policy lead to sustainability of cities? [J]. Land Use Policy, 2018, 73: 49-58.

[16] Castelnovo W, Misuraca G, Savoldelli A. Smart cities governance: The need for a holistic approach to assessing urban participatory policy making [J]. Social Science Computer Review, 2016, 34(6): 724-739. 